\title{
APARÊNCIA, SER E FORMA: A ONTOLOGIA DO ESPAÇO EM ARMANDO CORRÊA DA SILVA
}

\author{
ANTONIO BERNARDES ${ }^{1}$ \\ Universidade Federal Fluminense
}

\section{INTRODUÇÃO}

Armando Corrêa da Silva nasceu em Taquaritinga, Estado de São Paulo, em 26 de novembro de 1931. Faleceu na cidade de São Paulo, em 26 de agosto de 2000. Bacharelou-se em Ciências Sociais e obteve o título de doutor em Geografia pela atual Faculdade de Filosofia, Letras e Ciências Humanas da Universidade de São Paulo, da qual, posteriormente, foi docente no Departamento de Geografia.

Foi militante comunista e um boêmio que costumava tocar piano nos bares de São Paulo e fazia algumas "canjinhas" nos encontros da AGB (Associação dos Geógrafos Brasileiros). Ele participou ativamente do Movimento Geografia Crítica no Brasil e publicou vários textos sobre os mais variados temas - Geografia Política, Geografia Regional, Geografia Urbana, Epistemologia em Geografia, Ontologia em Geografia etc. -, dos quais destacamos para esta discussão os de epistemologia e ontologia em Geografia como, por exemplo: "O espaço fora do lugar" (1978), sua tese de livre-docência, intitulada "Cinco paralelos e um meridiano" (1979) e "De quem é o pedaço" (1985).

Tanto os livros como a sua tese de livre-docência são formados por um conjunto de artigos que, por sua vez, se caracterizam por serem curtos, densos e com poucas referências. Pela erudição e o espírito artístico de

\footnotetext{
${ }^{1}$ Prof. Adjunto do Departamento de Geografia Universidade Federal Fluminense Campos dos Goytacazes-RJ

E-mail: antoniobernardes@id.uff.br
} 
Silva, entendemos que essa forma de concepção textual era proposital, todavia, ela não facilita a instrumentalização teórica para o desenvolvimento dos estudos geográficos. Mesmo considerando que muitos dos temas trabalhados em suas obras mais antigas foram retomados em outras posteriores de modo mais aprofundado, mas, não necessariamente, mais sistematizados.

Em outro momento, empreendemos uma pesquisa bibliográfica e documental das obras de Silva (BERNARDES, 2012) no intuito de delinear uma lógica que perpassa as suas principais propostas teóricometodológicas. Dos livros, artigos científicos e rascunhos consultados, o texto que mais nos auxiliou foi o artigo "Aparência, ser e forma: Geografia e método" (1996) ${ }^{2}$, pois nele há o desenvolvimento explícito e sistematizado de uma proposta teórico-metodológica para os estudos geográficos, com debate teórico com os principais pensadores que o influenciaram.

O estudo, de boa parte das obras de Silva com que tomamos contato, foi orientado por esse texto (SILVA, 1996), o que nos permitiu nos ater à estruturação lógica de suas propostas teóricas para entender o modo de concatenação das categorias e dos conceitos. Para tanto, quanto mais nos aprofundávamos nas discussões propostas por Silva, mais nos remetíamos a suas influências filosóficas. Algumas proposições de Sartre - a teoria da nadificação e as estruturas cognitivas do ser-no-mundo, tais como: Ser-emsi, Ser-para-si e Ser-para-outro -, e outra de Lukács - a contradição entre o singular, o particular e o universal - foram as que nos orientaram para o estudo mais aprofundado das principais proposituras teóricas de Silva.

Nesta discussão objetivamos realizar um procedimento similar. Identificar, interpretar e discutir algumas das principais influências filosóficas no desenvolvimento das proposituras teóricas desenvolvidas por Silva, ao mesmo tempo em que buscaremos delinear e apresentar uma lógica interpretativa, para os estudos em Geografia, que perpassa seus diversos textos. Em verdade, a sistematização das principais propostas teórico-metodológicas de Silva foi baseada na correlação das proposições teóricas desenvolvidas no texto "Aparência, ser e forma: Geografia e método" com as defendidas pelos filósofos destacados.

${ }^{2}$ Este artigo foi publicado posteriormente na Revista GEOgraphia sob o título "A aparência, o ser e a forma: (Geografia e Método)" (SILVA, 2000, p.7-25). 
Ao lançarmos mão de certas interpretações filosóficas para entender e sistematizar algumas das propostas teóricas de Silva de modo mais conciso e coeso, indicamos nosso objetivo neste texto: colocar em debate a ontologia do espaço desenvolvida por Silva como uma das maneiras de tratar o ser-do-homem no mundo ou o ser-no-mundo ${ }^{3}$ e seu modo de fundamentação para os estudos geográficos. ${ }^{4}$ Mas, de que modo as discussões acerca da ontologia do espaço e o entendimento quanto ao modo de fundamentação do ser-no-mundo podem contribuir para as discussões geográficas?

Em concordância com Silva, afirmamos que se trata de "um procedimento pluralista e interdisciplinar que consiste em produzir o discurso no momento de pensá-lo como informação e comunicação, capazes de permitir a expressão do significado e do significante" (SILVA, 1996b, p.80). Ou seja, entendemos que Silva utilizou certos procedimentos comuns à gnosiologia, à ontologia e ao existencialismo para colocar em debate na Geografia como e de que modo os homens como ser-no-mundo pensam e objetivam seus pensamentos no lugar de sua existência. Há uma mudança na perspectiva de abordagem daquilo que tradicionalmente atribuímos como objeto de estudo da Geografia. Silva coloca em discussão como o ser-no-mundo percebe e apreende o lugar de sua existência e o objetiva seus pensamentos enquanto ser social, ou seja, ele coloca em discussão o processo cognitivo e seus modos de objetivação ao invés de se

${ }^{3} \mathrm{O}$ conceito filosófico de ser-do-homem ou o Dasein é trabalhado por Sartre e Heidegger para indicar o ser de determinada essência, a existência. No caso, a existência humana que, por sua vez, é a dimensão singular do ser, a estrutura relacional e sintética com a sua alteridade, que está no mundo. O estar indica a existência e o ser a essência, assim, serno-mundo é colocar como princípio a contradição entre a consciência e a exterioridade imediata. Esse conceito indica de uma só vez a facticidade de ser estando no mundo ao mesmo tempo em que o mundo é fundado e fundante para o ser (HEIDEGGER, 2011; SARTRE, 1997)

${ }^{4}$ Trata-se de apenas uma possibilidade de interpretação das proposituras desenvolvidas por Silva, pois poderíamos desenvolver uma análise voltada somente acerca de suas contribuições teóricas para Geografia em determinado contexto histórico ou mesmo aferir a pertinência teórico-metodológica de suas proposituras. Todavia, nosso objetivo é mais modesto; está em apresentar, entender, interpretar e sistematizar algumas proposituras teóricas de Silva em que a ontologia do espaço e os modos de ser-no-mundo para os estudos geográficos estejam em destaque. 
deter ao entendimento das intencionalidades atribuídas aos objetos e o modo como elas influenciam na existência do ser-no-mundo.

Desse modo, convidamos os leitores para percorrer o caminho que nos possibilitou entender algumas proposituras teóricas de Silva e debater suas ideias em que o maior desafio foi e é colocar de lado a perspectiva de pesquisadores que somos - se é que isso é possível - para nos colocarmos, antes de tudo, como presença mundana. Em verdade, a perspectiva do serno-mundo que sou precede e fundamenta a do pesquisador que sou, por mais que ambas sejam indissociavelmente contraditórias, ela é a única que posso conceber objetiva e subjetivamente.

\section{ONTOLOGIA-FENOMENOLÓGICA ESTRUTURAL}

Ao analisarmos o artigo "Aparência, ser e forma: Geografia e método", notamos que Silva expõe de modo explícito e sistematizado a estrutura de uma proposta teórico-metodológica que é subjacente ao entendimento do processo cognitivo para os estudos geográficos.

Ele atribui certa dinâmica às categorias aparência, ser e forma para entender o movimento do pensamento, em que cada categoria geográfica é considerada como um nível de entendimento do ser-no-mundo. $\mathrm{O}$ movimento de pensamento é desenvolvido por contradições que vão da categoria paisagem à categoria espaço que são correlatas, respectivamente, às categorias aparência e forma.

Já a proposta teórica está amparada na correlação de princípios da fenomenologia, da ontologia e do estruturalismo (SILVA, 1996). Numa primeira aproximação, podemos propor uma correlação: a aparência à fenomenologia, o ser à ontologia e a forma ao discurso estrutural. Não que essa associação seja destituída de sentido, mas se reter somente a ela para o entendimento desta propositura é não destacar o modo como pode ser possível interpretar, representar e entender o movimento do real pelo serno-mundo para os estudos geográficos.

Desse modo, cabe avançarmos por partes. Num primeiro momento, indicaremos brevemente algumas das influências ontológicas e fenomenológicas que orientaram Silva e, em seguida, a articulação entre as categorias aparência, ser e forma. Quanto à interpretação estrutural, ela será abordada mais adiante enquanto forma. 


\section{Breve excurso quanto à ontologia e a fenomenologia}

Entendemos que a ontologia, do modo que é utilizada por Silva, está próxima à maneira proposta por Heidegger, na medida em que, "a ontologia clássica, por exemplo, a de Lukács e N. Hartman, não dá conta da forma real e da forma aparente" (SILVA, 1997b, p.2) e pressupomos que, tampouco, as de Aristóteles e de Husserl. Silva não utiliza a ontologia aristotélica, ou melhor, a sua metafísica ${ }^{5}$ pelo simples motivo de que ela é um dos núcleos do impasse que ele identificara para a Geografia, no qual a taxonomia é um dos seus princípios (SILVA, 1988).

No que concerne à utilização de princípios da fenomenologia, entendemos que Silva está de acordo com o modo desenvolvido por Sartre, principalmente, em sua obra "O Ser e o Nada", em que ele busca dialogar com a fenomenologia de Husserl e a ontologia de Heidegger. Sartre utiliza de Husserl o procedimento que busca evidenciar o processo entre a consciência e a exterioridade imediata que leva os homens ao conhecimento do mundo enquanto relações de relações dos objetos e dos fenômenos; de Heidegger, ele toma o conceito de ser-no-mundo na tentativa de evitar o solipsismo husseriano.

Silva desenvolve sua proposta teórica, a que ele denomina de fenomenologia-ontológica estrutural (SILVA, 1996), amparada por correlações de uma miríade de princípios filosóficos de distintas vertentes. Delineamos minimamente as referências para a ontologia e fenomenologia, contudo para o estruturalismo ou a interpretação estrutural não temos tão claras as suas principais referências, as quais devem ser exploradas em outro momento. Por ora, entendemos que ele aborda o aspecto estrutural da realidade em sentido similar ao trabalhado por Santos (1996): os objetos, ocorrendo, cada vez mais, em conjunto e carregados de intencionalidades que the foram atribuídas, podem orientar o cotidiano dos homens. A interpretação estrutural é o âmbito da forma na propositura de Silva e para a alcançarmos é necessário expor e debater o movimento de pensamento do

${ }^{5}$ Ao longo da História da Filosofia a metafísica, a teoria do conhecimento e a ontologia são facilmente associadas quando se considera que seu desenvolvimento se erige sob um questionamento similar: O que é o mundo? Quem é o homem? Contudo, não devemos confundi-las, para não negligenciar a própria especificidade histórica desse desenvolvimento. 
ser-no-mundo e é pelo desenvolvimento do silogismo ${ }^{6}$ aparência, ser e forma que essa referência se tornará mais clara.

\section{Aparência, ser e forma: desenvolvimento de um silogismo}

Pela articulação entre as categorias aparência, ser e forma Silva aborda o movimento de pensamento do ser-no-mundo, desde o seu modo elementar e imediato - a objetividade subjetivada - até o seu modo concreto e mediato - a objetivação de certa subjetividade na matéria, que é a objetividade da matéria trabalhada, que pressupõe uma objetivação.

A articulação dessas três categorias e o movimento de pensamento que se busca abordar é o que nos permitiu determiná-la como um silogismo concreto. Nossa assertiva ganha corpo, notadamente, quando Silva (1996b, p.80) afirma que "decifrar a forma, que é resultado e ponto de partida, implica ter o ser como referência analítica, mas que só se mostra como aparência". Entendemos que se trata de um esforço de colocar o modo de conhecimento do ser no centro do debate em Geografia. Consideram-se dois momentos qualitativamente diferentes da categoria forma e a indicação do movimento de pensamento do ser-no-mundo. O primeiro momento é a forma enquanto aparência e, o segundo, ela dotada de certo conteúdo.

Quando determinamos que a lógica trabalhada por Silva trata de um silogismo concreto, isso implica considerarmos que a premissa menor é a aparência, que é o imediato; o termo mediador é o ser; e, a forma é a premissa maior, que é o concreto e mediato. É o ser quem atribui conteúdo a aparência e a desenvolve como forma, por isso ele é o termo mediador, pois “'recuperar a visão da aparência é o 'ver' carregado de subjetividade.

${ }^{6}$ De modo geral, um silogismo é composto por uma premissa maior, uma menor e um termo mediador. Quando realizado segundo a compreensão, não cai nos formalismos dedutivistas dos silogismos clássicos, como: "Todo homem é mortal; ora, Sócrates é homem; logo, Sócrates é mortal." (LEFEBVRE, 1975, p.153-154). O silogismo baseado na compreensão congrega determinado entendimento de mundo segundo os momentos do pensamento e as dimensões de análise do real - universal, singular e particular -, por exemplo: "Todo Estado que, em seu crescimento, ultrapassa certos limites, dirige-se para sua perda; ora, a Roma imperial ultrapassou seus limites; logo, a Roma imperial dirigiu-se para a sua perda." (LEFEBVRE, 1975, p.157). Eis um silogismo da necessidade, que é um silogismo concreto, um silogismo histórico. 
O espaço-tempo vivido é, assim, apenas uma mediação. Há que ultrapassar o seu significado empírico, para a ideia se repor como ideia, ou seja, como abstração" (SILVA, 1996a, p.114).

Reiterando nossa assertiva, sob os termos utilizados por Silva, temos: ao ultrapassar o significado empírico - aparência - para a ideia se repor como abstração - forma - se indica o movimento do pensamento que só é possível pelo ser-do-homem no mundo que vivencia certo espaço-tempo. Seguindo, ele coloca que
A aparência é o ver, o olhar, o enxergar, o observar, o pensar e o refletir externos a consciência, ante a qual se põe. [...] $O$ ser dá conta da interioridade do olhar, do ver, do enxergar, do observar e do refletir. Não as palavras, agora, mas as categorias e os conceitos.
Mas, há uma teoria e método da aparência e uma teoria e método de ser, cuja articulação deve ser feita, na passagem do abstrato ao concreto.
Ora, há que retornar ao abstrato, então como modo. É o âmbito da forma. Mas, em movimento. (SILVA, 1996b, p.79)

Entendemos que a aparência é o elemento primeiro do silogismo porque ela indica o ver, o enxergar, o observar, o pensar e o refletir ante a qual se põe a consciência. Em outras palavras, a aparência é pela relação contraditória de certa consciência para matéria e quando refletida, pensada, essas representações são categorias e conceitos - forma. A aparência é o abstrato e o conteúdo que o ser dotado de consciência atribui a ela a repõe como conhecimento concreto. $\mathrm{O}$ aparente é um objeto real separado de seu significado para o ser. Para ultrapassar a aparência, é necessário vivenciar o lugar. Muda-se o objeto e se muda o ser. Emerge a forma como aparência pensada. É o ser quem medeia, atribui sentido e valor a essa relação.

Silva abordou a questão acerca da aparência sob outros modos e por meio de um deles, podemos avançar na discussão para expor com mais clareza o que é a aparência e como o ser lhe atribui conteúdo.

O ponto de partida é a consideração da abstração em si mesma como objeto. [...] Ela se pondo à mente como vazio, que é aspecto do real concreto em si. O vazio é o nada, que a 
praticidade do universo identifica como uma forma real do existir. O nada pode ser pensado como não-ser. O não-ser possui uma espacialidade relacional: os vazios são múltiplos. (SILVA, 1996a, p.99) (grifo nosso)

O movimento de pensamento que vai da aparência à forma ou do abstrato ao concreto possui como fundamento a contradição. Colocando-se a mente como vazio. Como negação da exterioridade. O vazio é o nada, mas não como nulidade, e sim, como um não-ser que possui uma espacialidade relacional com certo $\operatorname{ser}^{7}$ - neste caso, um objeto.

Silva estabelece o nada como um elemento do processo de fundamentação do ser em que a forma aparente é a primeira representação dessa relação como percepção da espacialidade. Entendemos que o nada ao modo utilizado por Silva decorre das considerações realizadas por Sartre e não das de Hegel - que considera o nada como a representação derivada da negação de determinado objeto, ou seja, a suprassunção de uma objetividade determinada - como segue.

Significa que, por um duplo movimento de nadificação, o interrogador nadifica com relação a si o interrogado, colocando-se em estado neutro, entre ser e não-ser, e ele próprio nadifica-se em relação ao interrogado, descolando-se do ser para poder extrair de si a possibilidade de um não-ser. Assim, com a interrogação, certa dose de negatividade é introduzida no mundo: vemos o Nada irrisar o mundo, cintilar sobre as coisas. Mas, ao mesmo tempo, a interrogação emana de um interrogador que se motiva em seu ser como aquele que pergunta, desgarrando-se do ser. A interrogação é, portanto, por definição, um processo humano. Logo, o homem apresenta-se, ao menos neste caso, como um ser que faz surgir o Nada no mundo, na medida em que, com este fim, afeta-se a si mesmo de não-ser. (SARTRE, 1997, p.66)

Sartre considera o nada ou o não-ser como uma forma de ser da objetividade que permite ao ser-no-mundo interrogá-la e negá-la para estabelecer o mundo e ele próprio enquanto ser. Ele evidencia a

${ }^{7}$ A partir deste momento abordaremos o ser de dois modos distintos: como objeto e como ser-do-homem. Quando se tratar do último caso ele virá em itálico. 
fundamentação do ser para a exterioridade imediata, pois considera que "a consciência não é o seu próprio motivo, sendo vazia de todo conteúdo, [...] a consciência se fundamenta se relacionando com o mundo" (SARTRE, 1997, p.78). Ou seja, ao focar nossa atenção em determinada objeto da exterioridade imediata - ser - ele emerge para consciência juntamente com todos os outros objetos deste campo material - não-ser -, porém de modo indiferenciado à consciência. Nenhum objeto ou coisa está especificamente designado para se organizar em ser ou não-ser: tudo depende da direção de nossa atenção. Seguindo o exemplo utilizado por Sartre (1997), ao procurar determinada pessoa em um bar, ela é o ser e o bar, com seus objetos, é o nada. Esta apreensão de "bar" em nada é uma nadificação. O bar com seus objetos tem atenção marginal e a nadificação de todos os seus seres é a condição de aparição do ser principal, a pessoa procurada.

Podemos considerar que a espacialidade relacional a qual menciona Silva é o nada que vem aos seres pela relação de ser. O ser-no-mundo atribui relação a seres que não possuem quaisquer relações inerentes entre si e quando o faz, há nesta exterioridade imediata, formada pelo ser e nãoser. A contradição que o constitui enquanto ser. É pelo processo de negação de determinada exterioridade imediata que nos constituímos e somos constituídos pelo mundo enquanto ser-Em-si e, por sua vez, constituímos o mundo como exterioridade imediata. Quando determinado objeto está em relação a nós no mundo, suprassumimos sua forma aparente como objeto para consciência, ser-Para-si. O Para-si é algo próximo ao que na psicanálise se denomina de consciente e o Em-si, como nadificação do Para-si, algo próximo ao inconsciente. ${ }^{8}$ A contradição entre o Em-si, o Para-si e o Para-Outro - que discutiremos mais adiante - é o ser-nomundo.

As primeiras nuanças do pensamento enquanto forma emerge ao ser pela relação contraditória entre o Em-si e o Para-si ou do ser-no-mundo para a exterioridade imediata; como reflexão da realidade. A consideração da totalidade do real submetida a uma interpretação geográfica subtotalidade - é este primeiro momento.

${ }^{8}$ Utilizamos essas considerações de Sartre (1997) acerca do modo de constituição do serno-mundo para expor suas estruturas cognitivas pela correlação com algumas denominações utilizadas pela psicanálise em caráter estritamente didático, pois ele as refuta. 


\title{
DA SUBTOTALIDADE AO TERRITÓRIO
}

Com base na discussão em torno da categoria aparência, em seu processo de desenvolvimento pelo ser em direção à categoria forma, entendemos que Silva determinará outro conceito fundamental para o desenvolvimento de sua propositura, a totalidade. Entendemos que ele o faz no intuito de resguardar o caráter cognitivo da explicação, mas dela realiza um recorte para a Geografia.

\begin{abstract}
A Geografia é uma subtotalidade. Ela pode ser identificada, no âmbito do conhecimento, como uma ideologia do cotidiano, expressa pela apreensão da espacialidade do valor relacional contido do real. Desse modo, apresenta-se, ao mesmo tempo, como uma essencialidade desse real e como sua manifestação externa. (SILVA, 1996a, p.99)
\end{abstract}

Entender a Geografia como uma ideologia do cotidiano não possui qualquer caráter depreciativo e, sim, se trata de indicar que o recorte temporal cabe ao geógrafo estudar, assim como, o modo como o pesquisador se situa para o pesquisado, no cotidiano. A espacialidade relacional é o recorte que fundamenta a subtotalidade e indica a Geografia como conhecimento parcial da realidade, objetivo e subjetivo; ou melhor, da totalidade se realiza um recorte para seu entendimento em Geografia.

A subtotalidade não se trata de um recorte arbitrário ou uma adequação da totalidade do real para os estudos geográficos. Consideramos que Silva opera esse recorte ao considerar que o arcabouço teóricometodológico da Geografia define certa particularidade para a singularidade dos fenômenos reais para uma interpretação científica pretensamente universal.

Realizamos esta assertiva com base nos pressupostos desenvolvidos por Lukács quando ele aborda os diferentes níveis de entendimento do real pelas categorias singularidade, particularidade e universalidade. Ele considera que as diferentes formas do conhecimento - notadamente, o científico e o estético - refletem a mesma realidade objetiva. A diferença está no modo como se desenvolve este conhecimento em conformidade com a proeminência de certos procedimentos da razão - dedução e indução 
- e suas respectivas formas de objetivação na matéria - analítica e sintética. Ou seja, a totalidade é singular, contudo, as interpretações podem ser particulares. (LUKÁCS, 1968).

Trazendo esses pressupostos de Lukács para a discussão, entendemos que quando Silva considera a subtotalidade é no sentido de uma totalidade submetida a uma interpretação geográfica, ou seja, é a totalidade interpretada pelas categorias e conceitos pertinentes à Geografia. Esse procedimento permite que se considere o ser-no-mundo e o seu movimento de pensamento ao mesmo tempo em que há uma interpretação particular que caracteriza as ciências, dentre elas, a Geografia.

A Geografia é uma interpretação particular da singularidade que é o real, adjacente à universalidade de suas categorias e conceitos. Tanto que consideramos a categoria aparência como uma primeira aproximação para esta subtotalidade. Trata-se das primeiras abstrações em direção à categoria forma, que terá seu conteúdo atribuído pelo ser-no-mundo. Trata-se de uma abstração concreta, num outro nível do entendimento.

\footnotetext{
Por isso, concluo que "o lugar determina a relação e viceversa, porque não existem lugares sem relações e relações sem lugares". O ponto de partida é, então, um complexo, uma totalidade.

Mas, a totalidade, no caso, é, então, a subtotalidade. (SILVA, 1979, p.XIII)
}

Silva, tanto para o texto de 1988 como para o de 1979 , considera que o ponto de partida para o estudo geográfico é a subtotalidade. Mas, por essa citação é posto um elemento novo para a discussão, a categoria lugar. Ao abordar a categoria lugar Silva indica o movimento de pensamento em direção à forma, notadamente, porque ela é abordada como um complexo de relações que é fundado e fundante pela relação do ser-no-mundo, pois há a necessidade do homem estar para ser. Ora, o estar implica uma localização do ser-no-mundo, pelo qual Silva traz para a discussão os conceitos de sítio, situação e posição em que seu fundamento é o habitat. (SILVA, 1988)

Em o "Espaço fora do lugar” (SILVA, 1988, p.11), Silva coloca que a necessidade do habitat se trata de um fenômeno de polarização que 
define para os grupos humanos a escolha do sítio que, por sua vez, ocorre pelas diversas formas de povoamento. A situação decorre da escolha do sítio que indica um conjunto de elementos físicos e culturais do lugar. Consideramos que estar em situação é ser perante um lugar e representá-lo como paisagem para que, pelo empreendimento do entendimento, se constitua como consciência espacial.

Pela obra "De quem é o pedaço", podemos aprofundar um pouco mais nesta discussão, como segue:
A partir daí a análise geográfica propõe que o espaço superfície da terra é o resultado de uma desigual combinação de fatores que se interagem e se equilibram gerando paisagens homogêneas (hoje, também de planejamento). O espaço superfície da terra é um resultado, mas é ele próprio o ponto de partida geográfico.
O espaço superfície da terra contém, desse modo, como dado natural e histórico, uma organização e uma estrutura próprias (uma forma espacial), que lhe conferem a característica ontológica de uma dimensão espacial de existência do natural e do histórico.
A dialética em Geografia é, então, uma dialética da forma?
Não parece ser tão simples assim.
É preciso prosseguir.
A dimensão espacial é uma unidade na multiplicidade: o lugar é único e múltiplo. É único e múltiplo em sua naturalidade e historicidade. (SILVA, 1986, p.92)

O espaço superfície da terra é o ponto de partida do estudo geográfico tal como é a subtotalidade em outras obras de Silva. A diferença está que nessa obra Silva nos traz outros elementos para discussão, ao afirmar que há um dado natural e histórico, uma organização e uma estrutura que conferem a característica ontológica da dimensão espacial. Nesse sentido, entendemos que ele considera que o espaço se manifesta no lugar para o entendê-lo, dialeticamente, como uno-múltiplo.

Restringindo-nos ao lugar, cada um dos seus aspectos, seja natural ou histórico, é para consciência um ser para um nada indiferenciado, pois ele congrega os aspectos naturais - físicos, climáticos, biológicos, culturais etc. -, e os históricos - os diferentes modos de apropriação do meio no 
decorrer dos diferentes períodos históricos, que incorre em diferentes formas de significação. As diferenciações das características do lugar só podem ocorrer porque o ser está em situação. Ele é estando sendo no mundo e isso indica a característica ontológica da dimensão espacial da existência, como dado natural e histórico.

A própria escolha do sítio incorre numa situação em que o habitat é seu fundamento. Habitar certo meio é fazê-lo o lugar das vivências cotidianas que implica estar e ser em determinado sítio e a posição em relação a outros sítios e a outros seres em situação, ou melhor, pela identificação de outros seres em situação, pressupomos seu sítio e sua posição, assim como, a nossa. Considerar essas características é buscar entender o lugar pelo passado, pois esses fenômenos já são objetividade. É pelo trabalho objetivado na matéria que se atribui intencionalidades aos objetos.

Os aspectos históricos do lugar emergem para o entendimento não somente como formas da exterioridade imediata, e sim, como determinada objetividade que tem seu fundamento no trabalho objetivado e possibilita a compreensão dos diferentes modos de apropriação do espaço pelos seres, conforme o período histórico e o desenvolvimento das técnicas.

[...] a forma espacial é a expressão do lugar, que é a riqueza real, assim como a população que o habita e trabalha.

Caberia a Geografia descrever e explicar esse espaço, pois é de espaço que se trata, mostrando que a forma espacial é apenas a manifestação visível (ou não) do espaço-superfície da terra - a paisagem percebida. Ora trata-se de compreendêla. (SILVA, 1986, p.95)

Silva coloca que cabe à Geografia descrever e explicar o espaço, o qual possui como expressão a forma espacial ou a espacialidade, assim como, a população que o habita e que o transforma pelo trabalho. Já na obra "O espaço fora do lugar", ele coloca os conceitos necessários para realizar essa descrição e análise.

Para isso estabelece-se como objetivo a consideração da formação do espaço geográfico, de sua estrutura, de suas características, de seus processos e funções, de suas 
transformações e do significado desses elementos constitutivos do todo para a consciência humana. (SILVA, 1988, p.9)

Para Silva as estruturas são definidas pelas relações entre a sociedade e a espacialidade, como padrões organizativos vinculados aos modos de produção hegemônico; os processos e as funções estão vinculados à formação e à estrutura de determinado lugar que possa atrair ou repelir certos fenômenos; as transformações indicam as mudanças espaciais no tempo; o significado considera o modo como a objetividade representada por estes conceitos são colocadas para a consciência (SILVA, 1988).

Quando Silva considera os processos como uma forma de transformação do espaço geográfico indica não somente a ação de forças internas para determinado lugar, mas também, as externas e se afasta definitivamente de uma concepção que busca definir os espaços relativos ou regiões por suas homogeneidades e heterogeneidades. Trata-se de uma concepção do espaço como uno-multíplo; uno, porque é totalidade e múltiplo porque, pelo empreendimento do entendimento, há a enunciação de conceitos que permitem sua análise. Desse modo, o espaço não é tratado como um mosaico de regiões ou de espaços relativos e sim como representação da consciência para a exterioridade imediata, ele é categoria.

O primeiro pressuposto da teoria é a categoria, ou seja, a concreção do pensamento ao nível do universal. Por isso, movimento do pensamento, as categorias se sucedem no decorrer da afirmação ou da interrogação. Qual sua gênese?

Para responder a esta questão tem-se que perguntar qual o seu conteúdo. Ora, o conteúdo da categoria é o ser ao qual se refere, material ou imaterial.

O segundo pressuposto da teoria é o conceito, que implica em maior concretude do que as categorias.

De certo modo, o conceito é uma descrição teórico-prática da categoria e pode implicar uma definição.

Contudo, a definição é diversa do conceito. Ela é, de certo modo, o modo como se expressa a definição do conceito. (SILVA, 1999) 
A categoria é para Silva a concreção do pensamento ao nível do universal, ou seja, considerando que há níveis para o entendimento do real - singular, particular e universal -, a categoria é aquela que indica as abordagens mais gerais, ou melhor, fundamentais para certo fenômeno. Ela deve indicar o fundamento do ser, por isso, concreto, que é o abstrato na forma mais elevada do entendimento para o mundo.

Silva não encerra a análise acerca do espaço como certa forma expressa no lugar pelos conceitos de formação, estrutura, características, processos e funções, transformações e significados. Para abordá-lo como uno-múltiplo, ele coloca, na obra "De quem é o pedaço?", três diferentes concepções para se abordar o espaço: absoluto, relativo e relacional.

O espaço absoluto determina o relacional se é qualitativamente mais importante: ele contém dentro de si a hegemonia que o relaciona com outros espaços absolutos. $\mathrm{O}$ espaço relacional determina o espaço absoluto se, através da mediação do espaço relativo, pode modificar o espaço absoluto. Modificar o espaço absoluto é alterar-lhe as relações, de dentro para fora ou de fora para dentro. Como não existem espaços sem relações, desde logo a possibilidade de transformação está implícita no próprio espaço como ser. (SILVA, 1986, p.95)

Silva considera o espaço absoluto como abstrato e concreto; o relativo, porque existem relações entre os objetos; e, o relacional, conforme Leibniz, porque "um objeto existe somente na mediada em que contém e representa dentro de si as relações com outros objetos" (SILVA, 1986, p.96). O espaço absoluto determina qualitativamente o relacional quando levadas em conta as ações hegemônicas, ou seja, o modo de produção hegemônico respectivo a cada período. $\mathrm{O}$ espaço relacional pode determinar o absoluto quando, pelas ações atribuídas a determinados objetos, existem as contradições e elas determinam a relação entre os objetos. O espaço relativo é um recorte que permite a aferição das determinações entre os diferentes espaços.

O lugar compreendido como expressão da espacialidade indica os diferentes modos de conceber o espaço. Entendemos que pela concepção de espaço relacional e relativo de Silva é possível realizar uma análise sincrônica e diacrônica dos lugares. Sincrônica, porque, pela identificação 
dos aspectos naturais e históricos de determinado lugar, se pode relacionálos por suas semelhanças e diferenças para outros lugares, assim como o período em que foi concebido determinado objeto, diacronia. A análise diacrônica ainda possibilita que se levem em conta outras características do lugar enquanto forma espacial, o futuro.

No futuro, o lugar apresenta-se como espaço excedente, que
remete à consciência de território.
Por isso, o espaço externo como projeto realiza-se como
território da consciência, no próprio momento que ela
transcende. (SILVA, 1986, p.84)

Colocar que uma das características do espaço seja ele como excedente é tê-lo como projeto. O projeto excede a objetividade do espaço, mas este, por sua vez, só pode ser projeto pela práxis do ser-no-mundo. É pela práxis que emergem as intencionalidades dos objetos, que é o projeto do Outro objetivado na matéria. Eis a sua característica de excedente, porque as intencionalidades indicam um futuro, ou melhor, podem direcionar o exercício da práxis para fins que não são os nossos, assim como pode haver o consentimento do ser-no-mundo para determinada intencionalidade a fim de dinamizar suas ações, instrumentalidade.

A consciência acerca desse espaço externo ao ser, a qual menciona Silva, é mediada pela instrumentalidade e pelas intencionalidades atribuídas aos objetos. Trata-se do território da consciência (SILVA, 1986, p.84), que só é refletida quando o ser-no-mundo tem certa consciência que sua práxis, como uma possibilidade de ser, pode ser determinada pelas intencionalidades atribuídas aos objetos. Esse tipo de relação, seja qual forem os aspectos considerados, tem seu fundamento na contradição. É pelo conflito que elas emergem ao ser como um modo de ser-no-mundo. Eis um dos aspectos fundamentais da categoria território para Silva.

A categoria território é, pois, a primeira concretude do lugar. As relações sociais de produção são, então relações localizadas no território apropriado da natureza ou de outros por conquista, conforme o demonstra toda história humana até o presente. 
A divisão territorial do trabalho é, por isso, um aspecto da divisão social do trabalho. É a expressão espacial mais duradoura.

A categoria região é posterior ao território, porque a região é o território já ocupado e onde se desenvolveu uma organização do espaço que o torna determinação de um modo de vida. É por isso que a região é lugar em que se nasce ou ao qual se pertence. Tem uma grande força da inércia como lugar já estruturado. (SILVA, 1986, p.31)

Silva indica que o território é a primeira concretude do lugar. Ele remete ao modo de apropriação dos lugares pelos seres e, na sua instância mais genérica e concreta, há as relações sociais de produção. O primeiro modo de transformação do lugar pelo ser ocorre pelo habitat e pela sua própria práxis se revela as intencionalidades como uma forma de expressão do território.

Neste ponto podemos correlacionar a concepção de território com a de espaço relacional e relativo trabalhada de Silva. Considerando que são atribuídas intencionalidades aos objetos e estes podem influenciar de certo modo a práxis dos seres, é pela objetivação do conflito entre a práxis e as intencionalidades que há a especificidade do lugar. Mas, o lugar não pode ser definido somente pelas suas contradições internas, é necessário pensar além do lugar e aferir as contradições externas e suas influências no lugar e nos seres. Associa-se aqui a concepção de espaço relativo e a categoria região emerge como o lugar já ocupado e organizado, a qual determina o modo de vida, não somente per si, e sim, em perpétua relação com as outras. Eis porque Silva considera a categoria região como posterior ao território.

\section{PELO LUGAR, O ESPAÇO}

Quanto mais caminhamos em direção à forma, mais relações foram estabelecidas e mais concreto se tornou o pensamento do ser-no-mundo. Nesse percurso, cada categoria geográfica indicou um nível do entendimento para fenômenos e relações específicas do real. O ser está situado no mundo e seu principal centro de referência é o lugar e é pelo lugar que entendemos que Silva estabeleceu a paisagem, o território e a 
região. Todas essas categorias geográficas são concreções do pensamento e em que seu nível mais abstrato, enquanto forma, há o espaço geográfico.

O espaço se expressa no lugar como espacialidade, neste momento, diferentemente da abordagem anterior, como concreto. Isto se deve, porque é no lugar que houve as relações significativas do ser-no-mundo, em que a paisagem é sua representação e a consciência territorial se desenvolveu pela territorialidade do lugar. A espacialidade foi estabelecida pela vivaz e perpétua contradição entre a práxis e as intencionalidades. A região é o espaço territorializado.

Contudo, levando em conta as obras de Silva, podemos abordar o espaço geográfico segundo duas concepções: pela primeira, mantemos o lugar como centro de referência do ser-no-mundo (SILVA, 1996a; 1996b) e pela segunda, imergimos pela categoria região, entendendo-a como um espaço relativo (SILVA, 1979; 1975). Por uma coerência lógica do que foi discutido, devemos prosseguir o debate tendo o lugar como referência do ser-no-mundo. Posição respaldada na citação anterior de Silva, pois "a região é lugar em que se nasce ou ao qual se pertence. Tem uma grande força da inércia como lugar já estruturado." (SILVA, 1986, p.31) Este é o caminho que iremos percorrer: a região entendida como um lugar ao qual o ser-no-mundo pertence e que possui certa inércia - intencionalidade - nos seus modos de existir. Trata-se de um espaço territorializado, em que a espacialidade se expressa no lugar.

Novamente tomamos de empréstimo outra discussão desenvolvida por Sartre (1997, p.287-384) que nos possibilitou entender o espaço territorializado que se expressa no lugar como mencionado por Silva. Trata-se do Para-Outro. Resguarda-se a relação do ser para a exterioridade imediata, só que a considerando de modo concreto, porque o ser-no-mundo já se deparou com as intencionalidades atribuídas aos objetos que, como subjetividade objetivada na matéria pelo trabalho, indicam Outro ser que a empreendeu.

O Outro está para Mim como representação de uma práxis objetivada na matéria e não enquanto ser-no-mundo pela sua facticidade de ser, ou seja, "em carne e osso". Estabeleço uma relação com o Outro indeterminado ao utilizar determinada ferramenta para efetivar meus projetos enquanto possibilidade de ser-no-mundo, podendo haver certo consentimento com os projetos do Outro - intencionalidade -, o que aufere instrumentalidade ao objeto. 
Por outro lado, o Outro não se revela somente pelas intencionalidades atribuídas aos objetos no decorrer da realização de tarefas corriqueiras, no dia-a-dia, no cotidiano, mas também como ser-nomundo o qual não sou. Sou para o Outro do mesmo modo que ele é para Mim, como Outro. Para haver o Outro e Eu é necessário haver uma negação recíproca, uma contradição recíproca, e um processo de dupla subjetivação. Percebemos o Outro por sua objetividade, ao mesmo tempo em que enuncia a sua subjetividade pelos projetos que empreendeu, e que fogem do meu conhecimento.

Desse modo, é possível considerar que o ser surge ao mundo com outros seres, que, também é um mundo para eles; num mundo já explorado e trabalhado, com significações que não foram atribuídas por este ser particular, mas que lhes comunicam e enunciam o seu devir. O lugar já está constituído e organizado, assim como, o tempo. Suas investidas no mundo necessariamente perpassam essa estrutura espaço-temporal. O ser só pode se escolher neste contexto de mundo em que ele próprio surge, não somente segundo a sua vontade e, sim, em conformidade com as intencionalidades estabelecidas.

Silva não menciona com as mesmas palavras o processo de contradição e de negação recíproca que buscamos expor do ser-no-mundo e do Outro, mas entendemos que ele indica este processo quando se refere à intersubjetividade e à linguagem como uma relação de ser e do reconhecimento do Outro que não é reificado pelo movimento entre significante e significado (SILVA, 1996a).

A linguagem se remete ao pensamento e o pensamento à linguagem, como a transcendência de um devir ou de um porvir pela situação presente. Destaca-se que a linguagem não se restringe à língua, e sim, é um modo de relação entre o significante e o significado. A partir dos conceitos de intersubjetividade e da relação entre o significante e o significado, Silva desenvolve os conceitos de comunicação e informação, como segue.

Comunicar a informação é, por isto, ir além do 'ver'. Implica em mudar o significante com o significado. A comunicação apreendida é a comunicação da qual se faz a leitura que mobiliza a abstração em direção a idéia nova. (SILVA, 1996a, p.104-105). 
A informação é exprimir ao Outro seus projetos como não sendo os Dele. É se colocar enquanto ser e consciência de mundo que foge ao conhecimento do Outro. A comunicação é um modo de exprimir determinada ideia concreta a partir de certa informação. As leis da linguagem são sustentadas e encarnadas pelo livre projeto concreto de seu conjunto simbólico organizado e, também, como conjunto de técnicas próprias que podem definir as atividades do ser-no-mundo.

Neste momento da discussão, a aparição do Outro como ser-nomundo pela sua facticidade de ser nos remete a compreendê-lo vinculado à forma ou ao concreto. Entendemos que, somente, quando há a concreção do pensamento para o entendimento e determinação do conflito entre a práxis e as intencionalidades, é possível abordar o Outro como intersubjetividade na propositura desenvolvida por Silva. É pela territorialidade que concebemos o Outro, seja pelas intencionalidades atribuídas aos objetos ou como ser-no-mundo factível. O ser surge num mundo em que o Outro é presença. Num mundo trabalhado e entre outros seres e considerar este processo de outra maneira é entender que ele surge num mundo desumanizado. Ora, mas nesta discussão, o Outro se faz de algum modo presente desde determinação de nossa localização, posição, sítio e situação, cujas só podem ser definidas por e para Outro. Esta é a condição de ser-no-mundo, com outros seres, com as coisas, no cotidiano.

Não há como desconsiderar o cotidiano, que é o pensar e fazer do dia a dia. Isto inclui a vivência diária, a memória e o imaginário das pessoas em sua relação com o lugar e com ele; a consciência da situação que não é alheia às diversas percepções e aos juízos de valores. As determinações do mundo em relação aos seres ganham corpo no âmbito do cotidiano, uma vez que ele lhes é inescapável.

É desenvolvendo o pensamento para esse conjunto de relações manifestadas no cotidiano que emerge a forma como consciência reflexa do mundo, ou melhor, como consciência refletida. É o ato da abstração trabalhado e em forma superior. Eis o reino da teoria. Para pensá-lo é necessário ter a razão como pressuposto e com ela, a abstração. A abstração reaparece não mais como nada, mas como ponto de partida para o raciocínio, como ideia concreta. $\mathrm{O}$ objeto deve refletir na consciência como ideia organizada, concreta. Então, pensar o espaço defronta-se com a espacialidade do lugar. A ideia organizada e concreta pode ser abordada de acordo com a categoria espaço, segundo Silva. 
Como o tempo e o movimento, o espaço é fundante do existir e, portanto, do pensar. Mas, essa constatação é resultado, desde logo de pensar o espaço. Pensá-lo como dado e pensálo como artefato que a mente projeta.[...] O espaço é o real e o imaginário. (SILVA, 1996a, p.117).

Pensar o espaço é dar concretude à ideia de espaço. É pô-la em movimento como elemento fundante e fundado da realidade humana. É captar o movimento da forma enquanto acumulação diversa e múltipla dos tempos e da relação contraditória dos fenômenos nas diversas escalas geográficas. Captar sua lógica de estruturação. No momento em que se desenvolve a consciência da forma, delineia-se uma ontologia de novo tipo, como consciência do espaço, uma ontologia do espaço.

Subjacente à ontologia do espaço há ontologia analítica, pois o "discurso é sempre prospectivo, buscando o imaginário no real, que contém a subjetividade e a objetividade, em direção à superação do horizonte enquanto máxima consciência possível" (SILVA, 1996b, p.80). Entendemos que a ontologia analítica é o cerne do silogismo aparência, ser e forma que, por sua vez, é a estrutura lógica da fenomenologiaontológica estrutural.

A ontologia do espaço em Silva é o movimento de pensamento que parte da relação do ser com a exterioridade imediata, identificando a espacialidade do mundo. Nessa relação com o mundo e com os outros seres, se estabelece um conjunto de relações que possibilitam o entendimento do modo de organização e estruturação dessas relações sob a denominação da categoria espaço.

Buscar o entendimento das relações de relações possíveis dos fenômenos do mundo é buscar organizá-lo na ideia de modo concreto, mas tendo a materialidade como pressuposto deste processo. Como, atualmente, cada vez mais, os objetos técnicos tendem a se apresentar num conjunto coerentemente organizado e a sua instrumentalidade só se efetiva por esee mesmo conjunto, é necessário abordar a realidade humana, também, por esea estruturação.

Pela aparência não é possível um entendimento estrutural das dinâmicas contraditórias do mundo. Por ela nos restringimos ao processo de significação que atribuímos aos objetos, indicando os lugares. É somente pela forma que há a possibilidade de realizar uma interpretação da 
realidade como estruturas de estruturas, em que a parte é o todo e o todo é a parte. A liberdade só é possível nesse contexto, quando entendemos a relacionalidade organizacional do mundo e a sua territorialidade.

Não só a consciência humana, mas também o comportamento,
começam a ser moldados com o objetivo de produzir no
máximo a percepção da utilidade. [...] Abstrair é, assim,
descoisificar, como ponto de partida o trabalho. Repondo-se o
nada, põe-se novamente a subjetividade. (SILVA, 1996a,
p.112)

Abstrair é ir além. O além é transcender à operacionalização dos objetos e dos sujeitos em direção a ter si próprio como sujeito do processo, que se defronta com a liberdade dos Outros e com as intencionalidades do mundo, pois, separando em sujeito e objeto, em pensante e pensado, o discurso não capta os conflitos entre as intencionalidades e possibilidades da práxis.

Silva destaca que se deve buscar a abstração num outro sentido que não aquele da instrumentalidade da matéria trabalhada para evidenciar a relacionalidade das coisas do mundo e a sua territorialidade. A matéria trabalhada deve ser entendida perante contexto de mundo para que seja possível aferir as intencionalidades para as possibilidades de ser sob certo distanciamento da dureza de sua instrumentalidade, que é sistêmica. Só desse modo é possível conceber o ser-no-mundo como demiurgo e criatura, ou seja, pela relação contraditória e fundamental que ele estabelece com o mundo e não como mais um elemento que constitui a estrutura que organiza o mundo.

\section{CONSIDERAÇÕES}

Cada uma das categorias trabalhadas por Silva indica um modo de relação do ser com o mundo e um modo de concebê-lo. Num primeiro momento, como exterioridade imediata e posteriormente como concreto, como mundo pensado. A cada passo da aparência em direção forma buscamos correlacionar os diferentes conceitos e categorias geográficas como níveis de entendimento do ser-no-mundo. Desse modo, a ontologia do espaço proposta por Silva trata-se de uma abordagem para o 
entendimento da realidade baseada em certa instrumentalização teóricometodológica das categorias e dos conceitos tradicionais da Geografia e a realidade entendida por seu modo estruturação é a forma mais concreta. Ela indica o pensamento refletido do ser, a forma mais concreta, por isso, espacial.

Para se conceber a categoria espaço enquanto forma, o ser atribuiu conteúdo a uma série de relações contraditórias que ele desenvolve com o mundo em que o lugar é sua referência. O lugar é uno-múltiplo. É apropriado e carregado de intencionalidades e significados. É onde se torna possível o entendimento do mundo e de si próprio como ser-no-mundo. Teoricamente, a categoria lugar precede a de paisagem, de território, de região e de espaço. Não poderia ser diferente, na medida em que Silva busca desenvolver um discurso em que se coloca o ser-no-mundo e sua fundamentação como referência analítica que ocorre no lugar de sua existência.

Silva considera o espaço como a categoria que indica o concreto nos seus aspectos mais universais, mas que só tem sentido como consciência espacial, como espacialidade refletida pelo ser no lugar. É necessário estar em situação para ser, pois é no lugar em que se realizam as vivências cotidianas, cujos objetos são intencionais e carregados de significações. O primeiro modo de apropriação e representação desse lugar é destituído de concretude, mas há de se retomar o lugar, agora como concreto, como espacialidade. Como consciência espacial que indica a contradição perpétua entre as intencionalidades e possibilidades de ser pela práxis. Assim, entendemos que a consciência espacial é pressuposto fundamental da ontologia do espaço de Silva. O espaço é considerado como categoria do pensamento e, como tal, essencialmente diferente do conceito de superfície terrestre ou subtotalidade. É pelo empreendimento do entendimento do ser-no-mundo que ele emerge.

Por fim, o movimento de pensamento do ser-no-mundo abordado por Silva e que, de algum modo, almejamos entender e traçar uma concatenação lógica para esta discussão esteve apoiado em diversas de suas obras, destacadamente: "Aparência, ser e forma: Geografia e método", "O espaço fora do lugar" e "De quem é o pedaço?". O primeiro texto é aquele em que mais nos apoiamos, seja por desenvolver uma proposta teórico-metodológica explícita e com indicações de referências que nos permitiram estabelecer correlações diretas com algumas proposituras de 
Sartre e uma de Lukács, assim como, as de Husserl e Heidegger, mesmo que de modo marginal. Foi por meio dessas proposições filosóficas que melhor entendemos a lógica desenvolvida por Silva e que nos possibilitou conceber as categorias aparência, ser e forma de modo silogístico para indicar e analisar o movimento de pensamento.

Não temos dúvidas que há outros entendimentos e correlações possíveis para as proposituras teórico-metodológicas desenvolvidas por Silva. Optamos por um caminho, por discussões que abordavam diretamente o modo de ser-no-mundo para os estudos geográficos e que é, majoritariamente, o teor das discussões que encontramos em diversas obras de Silva. Ele é um dos primeiros geógrafos brasileiros a desenvolver discussões de caráter ontológico, notadamente, quando apontou que a Geografia desenvolve certo impasse - denominado de impasse aristotélicokantiano - que negligencia a fundamentação do ser-no-mundo, destituindo$\mathrm{o}$, de sua cognoscidade e o considerando-o como um elemento das estruturas socioespaciais (SILVA, 1979, 1988; MARTINS, 1996).

Nesse sentido, entendemos que, cada vez mais, se faz necessário retomarmos algumas das questões levantadas por Silva e o arcabouço teórico-metodológico que ele desenvolveu no intuito de possibilitar o melhor entendimento, principalmente, quando aos aspectos qualitativos de alguns fenômenos contemporâneos que hoje são abordados de forma insatisfatória e que não levam em conta a conscientização humana como um modo de se fazer geografia.

\section{APARÊNCIA, SER E FORMA: A ONTOLOGIA DO ESPAÇO EM ARMANDO CORRÊA DA SILVA}

Resumo: A partir do estudo, análise e interpretação de algumas obras de Armando Corrêa da Silva e de algumas das proposições filosóficas que o influenciaram, notadamente, Sartre e Lukács, expomos e discutimos as principais contribuições teóricas desenvolvidas por Silva para os estudos geográficos no intuito de sistematizá-las ou ao menos delinear a perspectiva de abordagem que perpassa as suas diferentes obras em que o lugar e o ser são as referências discursivas. Utilizamos como referência para esta discussão a proposição teóricometodológica de fenomenologia-ontológica estrutural e a dinâmica entre as categorias aparência, ser e forma, desenvolvidos por Silva. Esta última, 
submetemos à lógica de um silogismo concreto para o melhor entendimento de sua ontologia do espaço.

Palavras-chave: ontologia, ser, ser-no-mundo, Geografia, lugar, espaço

\section{APPEARANCE, BEING AND FORM: THE ONTOLOGY OF SPACE IN ARMANDO CORREA DA SILVA}

Abstract: Through the study, analysis and interpretation of some works of Armando Corrêa da Silva and some philosophical propositions that influenced him, notably Sartre and Lukács, were presented and discussed the main theoretical contributions developed by Silva for geographical studies. Were outlined and systematized the perspective of approach that permeates their works and that him indicated the place and the being as discursive references. The reference for this discussion was the theoretical proposition of ontology phenomenological structural and the relation between categories appearance, being and form developed by Silva. These theories were subjected to logic the concrete syllogism to the understanding of his ontology of space.

Key-words: ontology, being, being-in-the-word, Geography, place, space

\section{BIBLIOGRAFIA}

BERNARDES, Antonio H. Das perspectivas ontológicas à natureza do internauta: contribuição à epistemologia em Geografia. Presidente Prudente: UNESP-FCT, tese de doutorado, 2012.

HEIDEGGER, Martin. Ser e tempo. Petrópolis: Vozes, 2011.

LEFEBVRE, Henri. Lógica formal/lógica dialética. Rio de Janeiro: Civilização brasileira, 1975.

LUKÁCS, Georg. Introdução a uma estética marxista: sobre a categoria da particularidade. Civilização brasileira: Rio de Janeiro, 1968.

MARTINS, Élvio Rodrigues. Da geografia à ciência geográfica e o discurso lógico. 319 f. Tese (Doutorado em Geografia) - Faculdade de 
Filosofia, Letras e Ciências Humanas, Universidade de São Paulo, São Paulo, 1996.

SARTRE, Jean-Paul. O ser e o nada. Ensaio de Ontologia Fenomenológica. Petrópolis: Vozes, 1997.

SANTOS, Milton. A natureza do espaço. Técnica e tempo. Razão e emoção. São Paulo: Hucitec, 1996.

SILVA, Armando Corrêa da. O Litoral Norte do Estado de São Paulo: Formação de uma Região Periférica. Tese. (Doutorado em Geografia) Faculdade de Filosofia, Letras e Ciências Humanas, Universidade de São Paulo, São Paulo, 1975.

SILVA, Armando Corrêa da. O espaço fora do lugar. São Paulo: Hucitec, 1978.

SILVA, Armando Corrêa da. Cinco paralelos e um meridiano. Tese. (Livre-docência em Geografia) - Faculdade de Filosofia, Letras e Ciências Humanas, Universidade de São Paulo, São Paulo, 1975.

SILVA, Armando Corrêa da. De quem é o pedaço. São Paulo: Hucitec, 1985.

SILVA, Armando Corrêa da. Aparência, ser e forma: Geografia e método. In: Geografia: modernidade e pós-modernidade. Presidente Prudente. (Apostila destinada ao curso de Pós-Graduação em Geografia da UNESPFCT, campus de Presidente Prudente), 1996a.

SILVA, Armando Corrêa da. Ontologia analítica: teoria e método. In: Geografia: modernidade e pós-modernidade. Presidente Prudente. (Apostila destinada ao curso de Pós-Graduação em Geografia da UNESPFCT, campus de Presidente Prudente), 1966b.

SILVA, Armando Corrêa da. O método da Geografia: uma ontologia do espaço? In: Geografia: modernidade e pós-modernidade. Presidente Prudente. (Apostila destinada ao curso de Pós-Graduação em Geografia da UNESP-FCT, campus de Presidente Prudente), 1996c. 
SILVA, Armando Corrêa da. Consciência espacial. In: Geografia e mudança cultural. São Paulo, 1997a. (Apostila destinada ao curso de PósGraduação em Geografia da FFLCH-USP), 1997a.

SILVA, Armando Corrêa da. Fenomenologia e cotidiano. In: Geografia e mudança cultural. São Paulo. (Apostila destinada ao curso de PósGraduação em Geografia da FFLCH-USP), 1997b.

SILVA, Armando Corrêa da. Simulando o espaço e o território. In: Geografia e mudança cultural. São Paulo. (Apostila destinada ao curso de Pós-Graduação em Geografia da FFLCH-USP), 1997c.

SILVA, Armando Corrêa da. Discutindo pressupostos. Presidente Prudente. (mimeografado), 1999.

SILVA, Armando Corrêa da. A aparência, o ser e a forma (Geografia e Método). GEOgraphia, ano II, n. 3, Niterói, UFF, 2000, p.7-25.

Data de submissão: 13/04/2012

Data de aprovação: 17/05/2013 